\title{
A Doença de Parkinson e o Processo de Envelhecimento Motor: Uma Revisão de Literatura
}

\author{
Parkinson's disease and the Process of Aging Motor: Literature Review
}

\begin{abstract}
Cheylla Fabricia M Souzal, Helayne Carolyne P Almeidal, Jomário Batista Sousa ${ }^{1}$, Pedro Henrique Costa ${ }^{1}$, Yonara Sonaly S Silveira ${ }^{1}$, João Carlos L Bezerra ${ }^{2}$
\end{abstract}

\section{RESUMO}

A doença de Parkinson (DP) é uma afecção do sistema nervoso central, a qual é expressa de forma crônica e progressiva. É resultante da morte dos neurônios produtores de dopamina da substância negra. Objetivo. Descrever os aspectos epidemiológicos, etiológicos, fisiopatológicos e os sinais e sintomas que estão integrados ao processo de envelhecimento neurológico, nos pacientes portadores da doença de Parkinson. Método. Pesquisa descritiva do tipo revisão bibliográfica. Conclusáo. A qual informou que o envelhecimento esta frequentemente associado ao comprometimento do desempenho cognitivo e fisiológico, o que integra o envelhecimento aos fatores que envolvem a etiologia da DP, sendo esta tida como idiopática, questóes ambientais e genéticas também a rodeiam o que tendem a repercutir no aparecimento de sinais e sintomas iniciais de natureza motora, interferindo diretamente na marcha e na execuçáo de movimentos.

Unitermos. Doença de Parkinson, Dopamina, Envelhecimento.

Citaçáo. Souza CFM, Almeida HCP, Sousa JB, Costa PH, Silveira YSS, Bezerra JCL. A Doença de Parkinson e o Processo de Envelhecimento Motor: Uma Revisão de Literatura.

\begin{abstract}
Parkinson's disease (PD) is a disorder of the central nervous system, which is expressed on a chronic and progressive. It is resulting from the death of dopamine-producing neurons in the substantia nigra. Objective. Describe the epidemiology, etiology, pathophysiology and signs and symptoms that are integrated with neurological aging process in patients suffering from Parkinson's disease. Method. Type a descriptive review. Conclusion. Which reported that aging is frequently associated with impaired cognitive performance and physiological, which integrates the aging factors involved in the etiology of $\mathrm{PD}$, which is regarded as idiopathic, genetic, and environmental issues also surround which tend to pass on appearance of initial signs and symptoms of physical disabilities, interfering directly in gait and movement execution.
\end{abstract}

Keywords. Parkinson's disease, Dopamine, Aging.

Citation. Souza CFM, Almeida HCP, Sousa JB, Costa PH, Silveira YSS, Bezerra JCL. Parkinson's disease and the Process of Aging Motor: Literature Review.

Trabalho realizado na Universidade Potiguar - UNP, Mossoró-RN, Brasil.

Brasil.

2. Fisioterapeuta, Especialista em Fisiologia e Cinesiologia do exercício, Docente do curso de Fisioterapia da Universidade Potiguar, Mossoró-RN, Brasil.

Endereço para correspondência: Cheylla Fabricia de Medeiros Souza Rua Francisco Solom, 81 - Boa Vista CEP 59607-330, Mossoró-RN, Brasil. E-mail: cheyllamedeiros@hotmail.com 


\section{INTRODUÇÃO}

O parkinsonismo é definido como uma vasta categoria de doenças que apresentam diminuição da neurotransmissão dopaminérgica nos gânglios da base, estando estas classificadas em: parkinsonismo primário, secundário, plus e heredodegenerativas. Sendo a doença de Parkinson a correspondente ao parkinsonismo primário descrita neste artigo $^{1,2}$.

A doença de parkinson é uma afecção crônica e progressiva do sistema nervoso, caracterizada pelos sinais cardinais de rigidez, acinesia, bradicinesia, tremor e instabilidade postural ${ }^{3}$. Apresenta uma etiologia idiopática, porém acredita-se que os seus surgimentos provem de fatores ambientais e genéticos, podendo interagir e contribuir para o desenvolvimento neurodegenerativo da $\mathrm{DP}^{4}$. Afirma-se ainda que o processo de envelhecimento está intimamente interligado a esta afecção devido à aceleração da perda de neurônios dopaminérgicos com o passar dos anos 5 .

O processo de envelhecimento é um fenômeno biológico normal na vida de todos os seres vivos e não deve ser considerado como doença. Apesar das doenças crônico-degenerativas, que podem acometer os indivíduos ao longo da vida. O sistema nervoso é o sistema biológico mais comprometido com o processo de envelhecimento, pois é o responsável pelo processamento de informações que visam manter a interação do indivíduo com o ambiente, e suas alteraçóes tendem a diminuir a força e a marcha apresenta-se mais retardada com diminuição de movimentos associados, reflexos profundos hiporresponsivos e alteraçôes de sensibilidade estão associadas às modificaçóes nos níveis anatômicos macroscópico, celulares e moleculares do sistema nervoso ${ }^{2,5}$.

O presente estudo objetiva descrever os aspectos etiológicos, epidemiológicos, fisiopatológicos e os sinais e sintomas apresentados no processo do envelhecimento que estejam relacionados aos pacientes com doença de Parkinson.

\section{MÉTODO}

Esta pesquisa é caracterizada como descritiva do tipo revisão bibliográfica. Foram incluídos nesta pesquisa artigos científicos, dissertações e teses referentes à doença de Parkinson encontrados nas bases de dados do Scielo,
Bireme, Medline, por meio das seguintes palavras-chave: Doença de Parkinson, dopamina, núcleo rubro, envelhecimento, marcha festinada, disfunção monoaminérgica múltipla e etiopatogênese da doença de Parkinson nos idiomas português e inglês, que correspondiam aos períodos de publicação dos anos de 2004 à 2010. Tendo esta pesquisa início em 10 de Abril de 2010 e concluída em 25 de Maio de 2010.

\section{RESULTADOS}

Foram encontrados 23 artigos científicos, dissertaçôes e teses além de livros didáticos de neurologia, geriatria e ortopedia da biblioteca, do setor de Fisioterapia da Universidade Potiguar, campus Mossoró.

A DP é uma afecção crônica, degenerativa e progressiva do sistema nervoso central, que decorre da morte dos neurônios produtores de dopamina da substância negra, consequentemente acarretando diminuição das células produtoras de dopamina na via negroestriatal e dos neurônios contendo neuromelanina no tronco cerebral, especialmente na camada ventral da parte compacta da substância negra e do lócus cerúleos. Essa alteração é caracterizada por distúrbios motores, disfunçóes posturais e cognitivas. Quando os sinais e sintomas são detectados, provavelmente já ocorreu a perda de aproximadamente $60 \%$ dos neurônios dopaminérgicos, e o conteúdo de dopamina no estriado é cerca de $80 \%$ inferior ao normal ${ }^{1,6,7}$.

\section{Epidemiologia}

$\mathrm{Na}$ literatura Nacional pesquisada, não foram encontrados artigos que apresentassem resultados de estudos epidemiológicos de modo válido da doença de Parkinson. Os dados obtidos foram por meio dos portais de dados epidemiológicos do Governo brasileiro, os quais registram que no Brasil, não existem estimativas oficiais, mas o IBGE - Instituto Brasileiro de Geografia e Estatística divulgou dados do último CENSO 2000, que a expectativa de vida aumentou pelo crescimento de $21 \%$ da população acima de 65 anos, propiciando estimar-se uma população de cerca de 200 mil indivíduos com DP. A prevalência em pessoas com idade entre 60 e 69 anos é de 700/100.000, e entre 70 e 79 anos é de 1500/100.000. No entanto, 10\% dos doentes têm menos de 50 anos e 5\% têm menos de 40 anos. Além disso, 36 mil novos casos surgem por ano no país ${ }^{7}$. 


\section{Etiologia}

A etiologia é tida como idiopática, mas estudos acreditam que a DP pode ser decorrente de um conjunto de fatores, sejam eles genéticos, toxinas ambientais, estresse oxidativo, anormalidades mitocondriais e/ou alteraçôes do envelhecimento ${ }^{2,4}$.

Os fatores ambientais estão interligados aos pacientes de DP que vivem em zona rural, fazem uso de água de poço e que estão mais expostos a pesticidas e herbicidas. As questóes químicas procedem de exposiçôes a produtos químicos industriais, como manganês, mercúrio e solventes. $\mathrm{O}$ estresse oxidativo ocorre quando existe um desequilíbrio entre os fatores que promovem a formação de radicais livres e os mecanismos de defesa antioxidativos. As questôes genéticas estão ligadas a existência de genes que favorecem o desenvolvimento da enfermidade, porém agindo de forma indireta. $\mathrm{E}$ as disfunçóes mitocondriais podem ser decorrentes de fatores tóxicos, bem como genéticos, que tendem a ocasionar uma cascata de eventos originando morte celular programada ${ }^{4,8,9}$.

Atualmente considera-se como fatores etiopatogênicos mais importantes a chamada causa multifatorial, ou seja, a combinação de predisposição genética com a presença de fatores tóxicos ambientais. Com relação à contribuição do envelhecimento cerebral, este estaria relacionado com a prevalência da idade, associada à perda neuronal progressiva ${ }^{10}$.

\section{Fisiopatologia}

A doença de Parkinson fisiopatologicamente deve ser considerada como uma afecção neurodegenerativa, progressiva, caracterizada pela presença de disfunçóes monoaminérgicas múltiplas, incluindo déficits dos sistemas dopaminérgicos, colinérgicos, serotoninérgicos e noradrenérgicos ${ }^{9}$.

O sistema dopaminérgico junto com os neurônios de melanina sofre despigmentação. Desta forma, subentende-se que quanto mais clara a substância negra, maior é a perda de dopamina. Associado a essa despigmentação tem-se a depleção do neurotransmissor dopamina que resulta da degeneração de neurônios dopaminérgicos da substância negra que se projetam para o estriado, onde são críticos para o controle do processamento da informação pelos gânglios da base, reduzindo a atividade das áreas motoras do córtex cerebral, desencadeando a diminuição dos movimentos voluntários ${ }^{9,11}$.

À medida que a doença progride e os neurônios se degeneram, eles desenvolvem corpos citoplasmáticos inclusos, que são os chamados corpos de Lewys, sendo estes corpos de inclusão citoplasmática dos eosinófilos, existentes na substância negra do mesencéfalo, os quais se aglomeram em grande quantidade ${ }^{3,5,9}$.

Ocorre ainda a perda das células do núcleo pedúnculo-pontino, combinada com a inibição aumentada do próprio núcleo pedúnculo-pontino, desinibe as vias retículo-espinhal e vestíbulo-espinhal, produzindo uma contração excessiva dos músculos posturais, estando estes relacionados aos déficits colinérgicos?

De uma maneira geral define-se com clareza a existência de uma perda neuronal progressiva no grupo de células ventro-laterais, da parte compacta da substância negra do mesencéfalo ${ }^{10,12}$.

\section{Sinais e Sintomas}

Para melhor compreensão sobre as áreas cerebrais acometidas na DP, dividiu-se em seis estágios. No estágio 1 ocorre o comprometimento do núcleo motor dorsal dos nervos glossofaríngeo e vago, além da zona reticular intermediária e do núcleo olfatório anterior, constituindo assim um processo neurodegenerativo quase que totalmente localizado nas fibras dopaminérgicas que inervam o putâmen dorso-lateral. No estágio 2, existe o comprometimento adicional dos núcleos da rafe, núcleo reticular gigantocelular e do complexo do lócus cerúleos. No estágio 3, observa-se o acometimento da parte compacta da substância negra do mesencéfalo. Já nos estágios 4 e 5 há comprometimentos das regióes prosencefálicas, do mesocórtex temporal e de áreas de associação do neocórtex e neocórtex pré-frontal, respectivamente. No estágio 6, ocorre o comprometimento de áreas de associação do neocórtex, áreas pré-motoras e área motora primária ${ }^{9,13}$.

Esses referidos comprometimentos manifestamse inicialmente de forma motora, onde são chamados de sinais cardinais da doença de parkinson. Sendo eles: rigidez, tremor, bradicinesia e instabilidade postural ${ }^{8}$.

O mecanismo responsável pelo aparecimento da síndrome rígido-acinética, geralmente é associado à presença de tremor e de instabilidade postural. Se da pela 
disfunção do sistema nigro-estriatal, com diminuição da concentração de dopamina ao nível dos receptores dopaminérgicos situados nos gânglios da base, no corpo estriado. Do ponto de vista de disfunção do circuito dos gânglios da base, observa-se perda de ação inibitória do segmento lateral do globo pálido sobre o núcleo subtalâmico, bem como existe uma ação hiperexcitatória do núcleo subtalâmico sobre o segmento medial do globo pálido, cujo resultado final será uma menor ação excitatória do tálamo sobre o córtex motor, determinando a síndrome rígido-acinética, a qual se apresenta de forma desigual em sua distribuição, afetando primeiramente os músculos proximais, especialmente ombros e pescoço, progredindo para os músculos da face, membros superiores e inferiores. Pode afetar inicialmente um lado do corpo, se alastrando até envolver todo o corpo, sendo que à medida que a doença progride se torna mais grave e diminui a habilidade dos pacientes se moverem, com facilidade ${ }^{3}$.

O tremor é tido como o sintoma inicial da DP. Em cerca de 50\% tem início nas extremidades distais, em decorrência de oscilaçôes involuntárias de uma parte do corpo. É observado em condiçóes de repouso que diminui ou desaparece com o início de alguma ação, podendo aparecer novamente quando o paciente mantiver uma ação ou postura mais prolongada ${ }^{6}$.

Acredita-se que a bradicinesia seja o resultado da ausência de dopamina no estriado, levando a um desequilíbrio entre os sistemas inibitórios e excitatórios, sendo que devido aos padróes de movimentos tenderem a uma alternância de excitação/inibição, o movimento tranca em uma direção com dificuldade de progressão o que leva a uma lentidão dos movimentos, especialmente os automáticos, havendo uma pobreza geral da movimentação e queixa frequente de fraqueza ${ }^{10}$. A bradiscinesia é o sintoma mais incapacitante de um DP, com a lentidão e o tempo prolongado de movimento, levando a um aumento da dependência nas tarefas cotidianas5.

Pacientes com DP apresentam anormalidades de postura e equilíbrio, assim a habilidade para manter uma postura estável pode náo estar comprometida em condições de equilíbrio sem perturbação e com atenção plena, e à medida que a base de apoio se estreita ou as demandas de atençâo variam, a instabilidade postural aumenta ${ }^{5}$. Isso se deve a perda de reflexos posturais. Os pacientes assu- mem uma postura muito característica com a cabeça e o tronco fletidos e tem muita dificuldade de ajustar a postura quando se inclinam ou quando há súbitos deslocamentos do corpo, o que favorece a ocorrência de quedas ${ }^{6,7}$.

Ocorrem também alterações na marcha, que se torna em bloco com características de festinada. Essa marcha festinada apresenta-se por passos curtos, rápidos e arrastados, sem a participação dos movimentos dos braços. Entende-se que essa marcha é em decorrência da postura adotada por estes portadores, pois a cabeça anterioriza-se, ocorre um aumento da cifose torácica com uma flexão de joelhos, onde o corpo adota uma postura que favorece a anteriorização do centro de gravidade $e^{4,10}$.

Devemos aqui relatar que a DP caracteriza-se não só pela deficiência exclusiva do sistema dopaminérgico, mas sim, por um comprometimento de vários outros sistemas monoaminérgicos, como os neurotransmissores serotonérgicos e o noradrenérgicos, representando, assim, uma síndrome clínica, patológica e bioquímica que pode ser desencadeada por diversos fatores genéticos e ambientais. Isto explica o surgimento de outros sintomas nãomotores, como distúrbio do sono (fragmentação do sono, apnéia do sono, sonolência diurna e síndrome das pernas inquietas), disfunção cognitiva e depressão, repercutindo em uma baixa qualidade de vida, tornando a DP ainda mais incapacitante e reduzindo a expectativa de vida ${ }^{9,13-15}$.

\section{DISCUSSÃO}

A senescência do sistema nervoso central (SNC) é uma das consequências fisiológicas mais comprometedoras, já que o mesmo é responsável por diversas funçóes como sensações de movimentos, psíquicas e biológicas internas, que alteradas interferem diretamente no funcionamento do SNC. Entre os 50 e 80 anos de idade ocorre à perda das transmissóes de impulsos nervosos, onde estes dependem de neurotransmissores para sua condução ${ }^{16}$. Dados epidemiológicos dos EUA mostram que a doença de Parkinson representa 80\% dos casos de parkinsonismo, acometendo de preferência pessoas acima de 50 anos. A prevalência é de aproximadamente 160 casos por 100.000 habitantes por ano e a incidência é de 20 casos pelos mesmos habitantes. Na idade de 70 anos, a prevalência é de 550 por 100.000 habitantes e a incidência é de 120 casos por 100.000 habitantes por ano ${ }^{1,2}$. Com os 
dados citados do IBGE-CENSO 2000, em que a prevalência em pessoas com idade entre 60 e 69 anos é de 700/100.000, e entre 70 e 79 anos é de 1500/100.000, mostra quanto a incidência no Brasil é quase quatro vezes maior em pessoas com menos de 70 anos e quase três vezes maior com pessoas a partir dos 70 anos $^{2}$. Mediante pesquisa epidemiológica Nacional e Internacional, constouse que o processo de envelhecimento está interligado a doença de Parkinson, pois a substância negra que contém a dopamina é um neurotransmissor dos neurônios dopaminérgicos que entre eles está o nigro-estriada, mesolímbica e mesocortical, já que a substância negra compacta é particularmente sensível ao envelhecimento em relação a outras estruturas cerebrais. A fase pré-sintomática ocorre nos primeiros 5 anos. A perda neuronal na substância negra compacta é cerca de $45 \%$ na DP, ao contrário de uma pessoa normal que é de $4,7 \%$ no processo de envelhecimento e consequentemente leva ao não suprimento de dopamina para os neurônios dopaminérgicos o que na via direta dos gânglios da base reduz a atividade das áreas motoras do córtex cerebral, diminuindo os movimentos voluntários. Quando o efeito da dopamina é diminuído a DP tende a manifestar-se, pois a falta da mesma resulta no aumento global da acetilcolina levando a um desequilíbrio entres estes neurotransmissores e ativando o processo de contração muscular, que ocorre quando há uma redução de $25 \%$ da atividade dos neurônios dopaminérgicos ${ }^{16,17}$.

A via nigro-estriada é a primeira a ser afetada, o que leva as características de alteraçôes motoras da doença como bradicinesia, tremor e rigidez. A via mesolímbica tem como função aprendizagem motivada pela recompensa, sensação de prazer e memória. Quando alterada observa-se alteraçóes comportamentais, como descontrole de impulso, depressão e pânico. A via mesocortical está envolvida na memória de trabalho e atenção onde sua disfunção manifesta-se por demência, psicose e déficit de atenção-hiperatividade ${ }^{12,17}$.

O metabolismo normal da dopamina produz radicais livres os quais na presença de depósitos de ferro no cérebro, poderiam resultar em neurotoxicidade por interferência da cadeia respiratória, suportando assim, a teoria de que a produçáo desses radicais livres pode ser uma causa da doença de parkinson ${ }^{10}$.

A hipótese da contribuição do envelhecimento cerebral na etiopatogenia da DP baseia-se na premissa da prevalência aumentada dessa enfermidade com o passar da idade, associada à perda neuronal progressiva. Nesta equação se associaria a presença de um agente tóxico, que desencadearia o processo de perda neuronal progressiva nos pacientes com $\mathrm{DP}^{9,17}$.

Um dos fatores fortemente contraditórios nesta hipótese é a perda neuronal progressiva observada na DP, ocorre predominantemente nas células ventro-laterais da parte compacta da substância negra do mesencéfalo, enquanto na senilidade existe uma perda neuronal progressiva mais evidente no grupo de células da parte ventro-medial e dorsal da parte compacta do mesencéfalo?.

\section{CONCLUSÃO}

Diante da revisão bibliográfica realizada, podemos afirmar que a doença de Parkinson é classificada entre as doenças degenerativas do sistema nervoso que manifestam a falência de dispositivos neuronais, como incapazes de se renovarem e, por isso, apresentam-se particularmente sensíveis ao envelhecimento.

$\mathrm{Na}$ atualidade consideram-se como fatores etiopatogênicos mais importantes as causas multifatoriais, ou seja, a combinação de predisposição genética com a presença de fatores tóxicos ambientais ${ }^{11}$. E associado a elas está o processo de envelhecimento, o qual tem associação direta a DP, devido à perda neural progressiva à medida que a idade avança.

Não podemos esquecer das disfunções dos sistemas dopaminérgicos assim como os monoaminérgicos, que são os sistemas colinérgicos, serotoninérgicos e noradrenérgicos, os quais são tidos como fatores importantes na apresentação da sintomatologia na DP, principalmente as alteraçôes motoras, pois essas causam limitações na vida desses idosos, que já se apresenta tão restrita a muitas tarefas, e essas limitaçóes tem despertado um sentimento de incapacidade, o que repercute em uma baixa qualidade de vida. 


\section{REFERÊNCIAS}

1.Lewis P, Prowland MD. Merrit tratado de neurologia. Rio de Janeiro: Guanabara-Koogan, 2007, p.768-83.

2.Pinheiro JES. Tratado de geriatria e gerontologia. Rio de janeiro: Guanabara, 2006, p.355-60.

3.O'sullivan SB, Schimitz TJ. Doença de Parkinson. Fisioterapia: avaliação e tratamento. São Paulo: Manole, 2004, p.747-73.

4.Pereira D, Garrett C. Factores de risco da doença de Parkinson um estudo epidemiológico. Acta Med Port 2010;23:15-24.

5.Rebelatto JR, Calvo JI, Orejuela JR, Portillo JC. Influência de um programa de atividade física de longa duraçăo sobre a força muscular e a flexibilidade corporal de mulheres idosas. Rev Bras Fisioter 2006;10:127-32.

http://dx.doi.org/10.1590/S1413-35552006000100017

6.Lana RC, Alvares LMRS, Nasciutti-prudente C, Goulart FRP, Teixeirasalmela LF, Cardoso FE. Percepçáo da qualidade de vida de indivíduos com doença de Parkinson através do pdq-39. Rev Bras Fisioter 2007;11:397-402.

7.Ilke D, Cardoso NP, Baraldi I. Análise da incidência de quedas e a influencia da fisioterapia no equilíbrio e na estabilidade postural de pacientes com doença de Parkinson. Rev Fisiot Brasil 2008;9:4-8.

8.Espindola AR. Avaliação respiratória em pacientes com doença de Parkinson submetidos ao método halliwick (monografia). Tubarăo: Universidade do Sul de Santa Catarina; 2005, p.1-86.

9.Teive HAG. Etiopatogenia da doença de Parkinson. Rev Neurocienc 2005;13:201-14.
10.Prado ALC. Avaliaçấo da memória emocional na doença de Parkinson (Monografia). Brasília: Universidade de Brasília; 2008, p.1-86.

11.Pieruccini-faria F, Menuchi MRTP, Vitório R, Gobbi LTB, Stella F, Gobbi S. Parâmetros cinemáticos da marcha com obstáculos em idosos com doença de Parkinson, com e sem efeito da levodopa: um estudo piloto. Rev Bras Fisioter 2006;10:233-9.

http://dx.doi.org/10.1590/S1413-35552006000200015

12.Palermo S, Bastos ICC, Mendes MFX, Tavares EF, Santos DCL, Ribeiro AFC. Avaliaçẫo e intervenção fonoaudiológica na doença de Parkinson. Análise clínica-epidemiológica de 32 pacientes. Rev Bras Neurol 2009;45:17-24.

13.Azevedo MM, Galhardo MC, Amaral AKFJ, Vieira ACC. Caracterização dos distúrbios cognitivos na doença de parkinson. Rev Cefac 2009;11:251-7. 14.Ferrão C, Dalbem A. O potencial terapêutico das células-tronco na Doença de Parkinson. Anais do X Salão de Iniciação Científica de Fisioterapia 2006; 10:806-7.

15.Silveira DN, Brasolotto AG. Reabilitaçáo vocal em pacientes com doença de Parkinson: fatores interferentes. Pró-Fono Rev Atual Cient 2005;17:241-50.

16.Peixinho A, Azevêdo AL, Simōes RM. Alteraçóes neuropsiquiátras da Doença de Parkinson. Rev Serv Psiquiatr Hosp Fernando Fonseca 2007;3:12-30.

17.Cardoso AS. Características estruturais e funcionais das redes de apoio social de idosos participantes e náo participantes de um programa de atividade física (dissertação). Florianópolis: Universidade do Estado de Santa Catarina - UDESC, 2009, p.1-163. 